\title{
The Relationship Between Kidney Size and Function in Short-Term Diabetic Patients
}

Dear Sir,

In a recent Letter to the Editor, Gundersen and Mogensen [1] presented a statistical evaluation of the available data from studies of glomerular filtration rate (GFR), renal plasma flow and kidney size in short-term Type 1 (insulin-dependent) diabetic patients. Their analysis led them to suggest that the major - perhaps even the sole - determinant of the increased GFR in short-term Type 1 diabetic patients is the increased kidney size. This suggestion may well be valid in clinically so-called well controlled diabetic patients, but it is certainly not so in poorly controlled subjects. Previous studies in poorly controlled Type 1 diabetic patients have demonstrated a $20 \%$ reduction in GFR during 1-2 weeks of improved metabolic control [2,3]. Recently, we studied GFR and kidney size (by ultrasound) in newly diagnosed Type 1 diabetic patients without ketoacidosis, before and after 8 days of strict metabolic control [4]. GFR was elevated by $44 \%$ before insulin treatment and remained $20 \%$ above normal after 8 days of strict metabolic control. The size of the enlarged kidney remained unchanged after 8 days of strict metabolic control. These data suggest that the elevation of GFR in poorly controlled Type 1 diabetic patients consists of two parts: rapid and slow reversible components of approximately the same order of magnitude. The rapidly reversible part can hardly be explained by morphological changes alone since kidney size was unchanged. Furthermore, the demonstrated increase in the glomerular filtration surface area (partly constituting one of the three well-known determinants of GFR) in newly diagnosed Type 1 diabetic patients also remains unaltered after 3 months of insulin treatment [5], a time by which a substantial decline in GFR would be expected.

It is documented that GFR in Type 1 diabetic patients can be increased or decreased within minutes in response to physiological changes in plasma levels of insulin, glucose and glucagon [6-10]. It is extremely unlikely that changes in kidney size can account for these rapid changes in GFR.

Studies in poorly controlled insulin-treated streptozotocin diabetic rats have shown that the elevated GFR is due to increased renal plasma flow, raised transglomerular filtration pressure, and probably also enlarged ultrafiltration coefficient (i.e. the product of the glomerular water permeability and the surface area available for filtration) $[11,12]$.

We conclude that the elevation of GFR in poorly controlled Type 1 diabetic patients consists of both rapid and slow reversible components. The rapidly reversible part, accounting for approximately half of the elevation, cannot be explained by the demonstrated enlargement of the kidney or of the glomerular surface area, but is due to an increase in the remaining two GFR determinants: renal plasma flow and transglomerular pressure. We agree with Gundersen and Mogensen that the slowly reversible part of the GFR elevation is probably due to enlargement of the kidney.

Yours sincerely,

J. Sandahl Christiansen and H.-H. Parving

\section{References}

1. Gundersen HJG, Mogensen CE (1981) The relationship between kidney size and function in short-term diabetic patients Diabetologia 21: 498-499 (Letter)

2. Mogensen CE, Andersen MJF (1973) Increased kidney size and glomerular filtration rate in early juvenile diabetes. Diabetes 22: 706-712

3. Parving H-H, Rutili F, Granath K, Noer I, Deckert T, Lyngsøe J, Lassen NA (1979) Effect of metabolic regulation on renal leakiness to dextran molecules in short-term insulin-dependent diabetics. Diabetologia 17: 157-160

4. Christiansen JS, Gammelgaard J, Tronier B, Svendsen PA, Parving H-H (1982) Kidney function and size in diabetics before and during initial insulin treatment. Kidney Int (in press)

5. Kroustrup JG, Gundersen HJG, Østerby R (1977) Glomerular size and structure in diabetes mellitus. III. Early enlargement of the capillary surface. Diabetologia 13:207-210

6. Mogensen CE, Christensen NJ, Gundersen HJG (1978) The acute effect of insulin on renal haemodynamics and protein excretion in diabetics. Diabetologia 15:153-157

7. Christiansen JS, Frandsen M, Parving H-H (1981) The effect of intravenous insulin infusion on kidney function in insulin-dependent diabetes mellitus. Diabetologia 20: 199-204

8. Brøchner-Mortensen J (1973) The glomerular filtration rate during moderate hyperglycaemia in normal man. Acta Med Scand 194: 31-37

9. Christiansen JS, Frandsen M, Parving H-H (1981) Effect of intravenous glucose infusion on renal function in normal man and in insulin-dependent diabetics. Diabetologia 21: 368-373

10. Parving H-H, Christiansen JS, Noer I, Tronier B, Mogensen C (1980) The effect of glucagon infusion on kidney function in short-term insulin-dependent juvenile diabetics. Diabetologia $19: 350-354$

11. Hostetter TH, Troy TL, Brenner BM (1981) Glomerular hemodynamics in experimental diabetes mellitus. Kidney Int 19: $410-415$

12. Jensen PK, Christiansen JS, Steven K, Parving H-H (1981) Renal function in streptozotocin diabetic rats. Diabetologia 21: $409-414$

Dr J.Sandahl Christiansen

Steno Memorial Hospital

DK-2820 Gentofte, Denmark

\section{Insulin Aggregation and the Use of Infusion Pumps}

Dear Sir,

A recent article in Diabetologia [1] recommended the use of a phosphate buffered (ph 7.0) highly purified insulin preparation in conjunction with EDTA treatment of the reservoir and tubing (to minimize metal ion contamination of the delivery system) in order to avoid the problem of insulin aggregation in artificial infusion de- vices. An earlier study [2] had shown that the ability of physiological fluids in vitro to dissolve crystals of insulin at a normal $\mathrm{pH}$ was dependent on the bicarbonate content. I wish to report a practical application of this latter observation to the problem of insulin aggregation in insulin infusion devices. 
I use the Delta pump [3], an open loop insulin delivery system which utilizes $\mathrm{U}-100$ regular insulin contained in a reservoir and propelled forward through the tubing by the repetitive action of a solenoid plunger pinching the area of tubing located between two check valves. The reservoir is usually refilled every 3-7 days depending on the patient's daily insulin requirement. Since the aggregation of insulin solutions had been described in implanted devices maintained at body temperature, I was surprised to meet this problem in the Delta open-loop pump. The precipitation seemed to start in either the tubing near the needle and/or in the tubing between the check values. Since the tubing adjacent to the subcutaneously placed needle is pressed against the skin, aggregation here is consistent with the association of this problem with higher temperatures [4]. The insulin contained in the area between the valves is subjected to the repetitive action of the solenoid plunger. Aggregation here is consistent with the association of this problem with agitation of the insulin solution [4].

To circumvent this problem, I initially dissolved glutamic acid $(50 \mathrm{mg} / 10 \mathrm{ml}$ vial) into the insulin under sterile conditions [5]. Although this prevented the aggregation, dissolving the dicarboxylic amino acid was difficult and some patients complained of burning at the needle site, especially during the administration of the preprandial bolus. After publication of reference 2, I used a physiological concentration of $\mathrm{NaHCO}_{3}(26 \mathrm{mmol} / \mathrm{l})$ to achieve the same end. To obtain this concentration, which is equivalent to $0.26 \mathrm{mmol} / 10 \mathrm{ml}$ vial, $0.3 \mathrm{ml}$ of the commercially available (at least in the USA) bicarbonate solution $(44.5 \mathrm{mmol} / 50 \mathrm{ml})$ is added under sterile conditions to a $10 \mathrm{ml}$ vial of $\mathrm{U}-100$ regular insulin. The addition of bicarbonate has been successful in preventing aggregation of the insulin solutions in the eight patients in whom this method has been used. The first patient was started nearly one year ago. Since aggregation seems to occur more readily when flow rates are low, it is particularly gratifying that this approach has been successful in a patient receiving $0.003 \mathrm{ml} / \mathrm{h}(0.3 \mathrm{U} / \mathrm{h})$.

Insulin aggregation has not been reported to be a problem with other open-loop insulin delivery systems (Mill-Hill and Autosy- ringe), probably because they use less concentrated insulin solutions. However, Autosyringe have modified their device so that now U-100 insulin can be utilized. If insulin aggregation becomes a problem in the tubing near the patient's body, the addition of physiological concentrations of $\mathrm{NaHCO}_{3}$ should be helpful.

Yours sincerely,

M. B. Davidson

\section{References}

1. James DE, Jenkins AG, Kreagen EW, Chisholm DJ (1981) Insulin precipitation in artificial infusion devices. Diabetologia 21: 554-557

2. Lougheed WD, Fischer U, Perlman K, Albisser AM (1981) A physiological solvent for crystalline insulin. Diabetologia 20 : 51-53

3. Siposs GG, Davidson MB (1981) A new open-loop insulin delivery system. Med Instrum (Baltimore) $15: 338-340$

4. Lougheed WD, Woulfe-Flanagan H, Clement JR, Albisser AM (1980) Insulin aggregation in artificial delivery systems. Diabetologia 19:1-9

5. Bringer J, Heldt A, Grodsky GM (1981) Prevention of insulin aggregation by dicarboxylic acids during prolonged infusion. Diabetes 30:83-85

M. B. Davidson, M.D.

Diabetes Program

Cedars-Sinai Medical Center

870 Beverly Boulevard

Los Angeles

California 90048, USA

\section{Aspects of Non-Enzymatic Glycosylation of Serum Proteins in Relation to Different Glucose Loads}

DearSir,

Svendsen et al. [1] and Bolli et al. [2], respectively, have shown rapid changes in the concentration of total stable and unstable glycosylated haemoglobin $\mathrm{A}_{1 \mathrm{c}}\left(\mathrm{HbA}_{1 \mathrm{c}}\right)$ and $\mathrm{HbA}_{1}$ to be dependent on short-term fluctuations in blood glucose levels. This phenomenon is regarded as representing the formation and dissociation of unstable $\mathrm{HbA}_{1}$ (aldimine-linked adduct), which is correlated with significant increases or reductions in glycaemic values.

Recently, non-enzymatic glycosylation of total serum proteins has also been shown to be increased in diabetic patients [3-5]. However, it has not been proven whether rapid changes in glucose levels in vivo and in vitro affect the level of glycosylated serum proteins [5]. We have therefore measured glycosylated serum proteins in ten normal subjects (aged $40 \pm 10$ years; mean \pm SD) and in 12 Type 1 (insulin-dependent) diabetic patients (aged $38 \pm 9$ years) after an overnight fast during an oral glucose tolerance test and several days later during a continous $5 \mathrm{~h} \mathrm{IV}$ infusion of glucose $(0.33 \mathrm{~g} / \mathrm{kg}$ body weight in a bolus $+0.9 \mathrm{~g} / \mathrm{min}$ in normal subjects and $0.6 \mathrm{~g} / \mathrm{min}$ in diabetic patients). Glycosylated serum proteins levels were determined by thiobarbituric acid reaction before and after dialysis of serum samples against $0.15 \mathrm{~mol} / 1$ saline solution $(1: 350)$ at $4{ }^{\circ} \mathrm{C}$ for $18 \mathrm{~h}$ (3). In the diabetic patients, the fasting glucose levels were higher $(8.1 \pm 3.1 \mathrm{mmol} / \mathrm{l})$ than in the normal subjects $(4.3 \pm$ $0.3 \mathrm{mmol} / \mathrm{l})$. Before dialysis, glycosylated serum proteins, expressed as nmol 5-hydroxymethylfurfural (5-HMF)/mg protein, showed values which were in parallel with the glycaemic values observed before and during the glucose loads. After dialysis, glucose was always $<0.2 \mathrm{mmol} / \mathrm{l}$ in samples from both groups, while 5HMF gave values lower than those observed before removal of glucose $(p<0.001)$. The mean fall was proportionate to glycaemic levels $(p<0.001)$. However, in every assay, diabetic patients showed higher 5-HMF values than normal subjects ( $p<0.001$, Table 1$)$. Moreover, after dialysis, 5-HMF levels were not significantly increased after different glucose loads. In normal and diabetic subjects, they ranged between 0.51 and 0.53 and between 0.93 and $0.97 \mathrm{nmol} 5-\mathrm{HMF} / \mathrm{mg}$ protein, respectively, during the oral glucose tolerance test with similar values during IV glucose infusion.

In agreement with the findings in vitro of Kennedy et al. [4], our observations in vivo indicate that the determination of glycosylated serum protein levels is influenced by free glucose present in the sample. However, as the oxalic acid used in the thiobarbituric acid reaction test induces rearrangement of the Schiff base [6], it cannot be excluded that the decreases in 5-HMF found after dialysis could 